\title{
An Exploration of Presidential Vocabulary by Year
}

\author{
Charles L. Becker \\ c.l.becker@outlook.com \\ 28 May 2020
}

This is not a formal research paper and I will not be presenting actual conclusions in response to my research question. This is better viewed a personal meta-research project, and a presentation of data and code resources that may be of use to those who are more accomplished than I am, especially in psychology, political science, and perhaps in economics.

All of the data and scripts referred to in this document are available at:

https://github.com/chasbecker/TextAnalysis I encourage the reader to visit that site and download the file "sotu_summary_by_prez.xlsx" which plots the output generated by Python scripts contained in "FunctionWords.ipynb".

Abstract During his 2020 State of the Union address, did President Trump use a vocabulary that was especially self-aggrandizing, or arising from insecurity or inferiority? Mining the historical records, I conducted a naïve analysis of presidential vocabulary from the founding to the present day. My conclusion is that Trump's use of first-person pronouns is not notably different from his recent peers, but along the way some possibly meaningful patterns in how presidents speak of themselves and of us did emerge.

\section{Preface}

During President Trump's state of the union address on February $4^{\text {th }}, 2020$, the impression came to me that he was using the vertical pronoun "I", and the objective "me" in an unusually high ratio compared to the plural forms, "we" and "us". My cultural background is in the military and the merchant marine, where leadership is an ever-present and immediate factor of social organization. The fundamental precept of leadership in those environments is "give credit, take blame"1. President Trump seemed to be doing the opposite. Realizing that I was experiencing this as it was occurring without time to digest, or a frame of reference regarding previous State of the Union addresses, I set out to investigate whether President Trump's vocabulary was unusually self-focused compared to his earlier speeches and those of other presidents.

\section{Literature}

1 "I'm the chief engineer of the thing," SpaceX CEO Elon Musk told CBS during a Tuesday interview. "So, I just like to say if it goes right, it's credit to the SpaceX and NASA team." But if anything "goes wrong, it's my fault," he added. 
The research on function words shows that these seemingly innocuous glue words, while providing little information on their own, do provide insight on the speaker's psychological perspective (Pennebaker). In Chapter 12 of Fiedler, Chung and Pennebaker explain the psychological component of function words. I found particular value for my research where they focused on interpretation of singular vs plural first person pronouns. Among many pertinent passages, these stood out:

They note, on p.350, an anticipation that as goals and context change, function word usage would follow, but report that the evidence shows otherwise. Interestingly, they note that in both men and women, elevated testosterone levels correlate with more "I" pronoun usage and as testosterone levels drop, "we" usage increases.

On p.352, Chung and Pennebaker draw a connection between social upheavals and the increased use of first personal plural pronouns, accompanied by a drop in first personal singular. They support this with an extensive analysis of the language used in blogs following the 9/11 attacks. They later note that in a dyad, the higher status person tends to use the first personal plural more than the lower status person does.

Of peripheral interest, they describe on p.356 that coercing a change in "I/we" usage, for example by mandating a speaker's substitution of "we" for "l", did not change the speaker's underlying psychological perspective.

\section{The Question}

"Did President Trump's 2020 State of the Union speech reveal elements of "acting tough" (i.e; real or imitated testosterone surplus), feelings of social inferiority, or a tendency toward unusual and notable self-centeredness."

\section{Sources}

Presidents generate vast amounts of written and transcribed communications. Some of those are extensively edited and carefully controlled, while others are ad hoc, impromptu, and composed as they are being spoken. Some presidential remarks actually seem to have been spoken before they were fully composed, in a sort of word cloud. To get a consistent metric over time, I identified the presidential State of the Union address as being a strong candidate for analysis. Samples for all presidents except William Henry Harrison are available. The report is required by the Constitution so the content is similar, although over time it has changed from a speech delivered verbally to a joint session of Congress, to a written report submitted to Congress, and back again. The timing of the speech has also changed relative to the presidential term, from late in the year (for that year) to a date usually in January (for the preceding year). 
There is also the question of whether impromptu, verbal remarks are more representative of a president's psychological state as compared to a speech as formal, edited, and curated as the State of the Union. In favor of the State of the Union addresses is both the consistency of performance and the diligent record keeping, allowing a more "apples-to-apples" comparison. Being so carefully groomed, these addresses afforded each president the chance to use language they felt most effective. The text of all these addresses is available in digital format, so I laboriously downloaded the full text for each of them (State of the Union).

\section{Methods}

Pennebaker has developed a highly proficient natural language analytic system called "Language Inquiry and Word Count" (LIWC) which provides a sophisticated analysis of texts along dimensions of gender, personality, and politics, among others (Pennebaker). Since this was a personal project, I rather cavalierly disregarded Chung and Pennebaker's caution against doing so and developed my own naïve word-counting technique.

Using the data generated by my apparatus, I built a dictionary of each president's entire state of the union vocabulary, sub-grouped by the year of the address. I have provided a hyperlink to the Python script used to do this, noting that the specific environment in that link is necessary for the script to run properly. Otherwise, modifications to the script to reflect a different directory structure will be required. The result was written out to "sotu.csv". The file structure is selfdocumenting.

I next wrote a Python script to calculate an "x/y" ratio based on two word lists: "x_words.txt" and

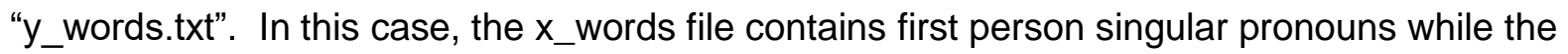
y_words file contains the plural forms. Thus, a higher ratio indicates relatively more first person singular pronouns; a lower ratio indicates relatively more first person plurals. The result was written out to "summary.csv". The file structure is self-documenting.

I loaded the dataset "summary.csv" into Excel and created a graphic representation of each president's pronoun usage ("AllPrez" tab). The "AllPrezGraph" tab graphically presents the usage of all presidents along a timeline. Finally, and perhaps most interestingly, is the "FDR" tab which graphs pronoun usage in Franklin Delano Roosevelt's twelve addresses during a turbulent period in world history.

\section{Observations of interest from the figure "State of the Union: I/we ratio by year"}

The first thing I found interesting is the pattern of usage over time: the data has noticeable heteroskedasticity and the "I/we" ratio has shifted over time. Except for Washington, our presidents through John Quincy Adams used the first-person plural at a low ratio $(<0.5)$. Then from Jackson through Wilson that ratio both increased to generally $>0.5$ and became more variable. Later, from Franklin Roosevelt through today, the ratio of the singular to plural has fallen below 0.5 and has remained remarkably consistent. Lyndon Johnson and George H.W. Bush each gave a single address with a notably high singular/plural ratio. 
While far from authoritative, I will offer my own speculation about what the story being told by the data.

1) Washington, Grant, and Taft stand out for how frequently they employed "I" relative to "we". The first two were combat generals who held office during the construction and reconstruction of the US. Taft was elected in the shadow of Theodore Roosevelt and faced relentless pressure from his predecessor.

2) In contrast, Eisenhower, a staff general, used a remarkably consistent mix of singular and plural pronouns, varying only between 0.2 and 0.3 across his nine addresses.

3) The period from Jackson through Wilson was tumultuous, bringing the United States from a nation that existed almost entirely east of the Mississippi to its present transcontinental condition. Perhaps this era brought to the fore presidents who responded with selfcenteredness, self-confidence, or some other psychological state particularly suited to advancing frontiers.

\section{Observations of interest from the figure "FDR: I/we Ratio vs Unemployment"}

Scanning the individual presidents' plots, Franklin Roosevelt's usage pattern simply jumps off the screen. Being aware of the Recession of 1937-38 (Recession), I was struck by how his pronoun usage changed so dramatically in a single year. The plot is normalized to 1934 levels, so indicates changes in level relative to that year. There are, of course, lags in the data since unemployment changes incrementally over a period of time while the State of the Union is a snapshot at one instant. But it is obvious that when unemployment spiked in 1938 that his usage of the first person singular plunged and he never regained his 1934 "I/we" usage ratio.

If the unemployment trendline from 1934-1937 is extended for five years, to 1942, it nearly intersects the unemployment curve at 1942, delimiting the period of FDR's lowest "I/we" ratio usage. It almost seems as if, when unemployment was higher than it "should" have been, FDR was motivated to use more inclusive language. While just uninformed speculation, that does provide a certain poetic sense to this.

It is curious to note that his fifth cousin, Theodore, followed the opposite pattern. Teddy's "I/we" ratio increased over time, from 0.1 to $>0.4$ throughout his second term.

\section{8. $\underline{\text { Conclusions }}$}

President Trump used the singular and plural first person pronouns in about the same ratio as his recent predecessors, albeit in 2020 at a higher ratio $(0.46)$ than in his previous addresses $(<0.3)$. In 2012, President Obama used a pronoun ratio of 0.46 , also in the last year of his first term, while his other addresses were quite similar to President Trump's. The objective data 
does not support my initial impression; this metric of his language did not reflect a particularly high level of self-centeredness.

So what happened? Perhaps I was wrong, and President Trump actually is an other-focused altruist. Or perhaps an analysis of the text does not capture the experience that a viewer or listener would have. I speculate that a phrase such as "I built this" can be delivered in ways that imply different things, leading the listener to infer different messages. Shifting the emphasis among each of those three words creates quite different meanings. President Trump's spoken delivery is notably different from that used by other presidents, politicians, academics, business leaders, or other serious individuals. That may have been what drove my initial negative impression.

\section{Exit}

As an indulgence of curiosity, this was an enjoyable and humbling learning experience. Thank you for reading, and your critical comments are will be warmly appreciated. 


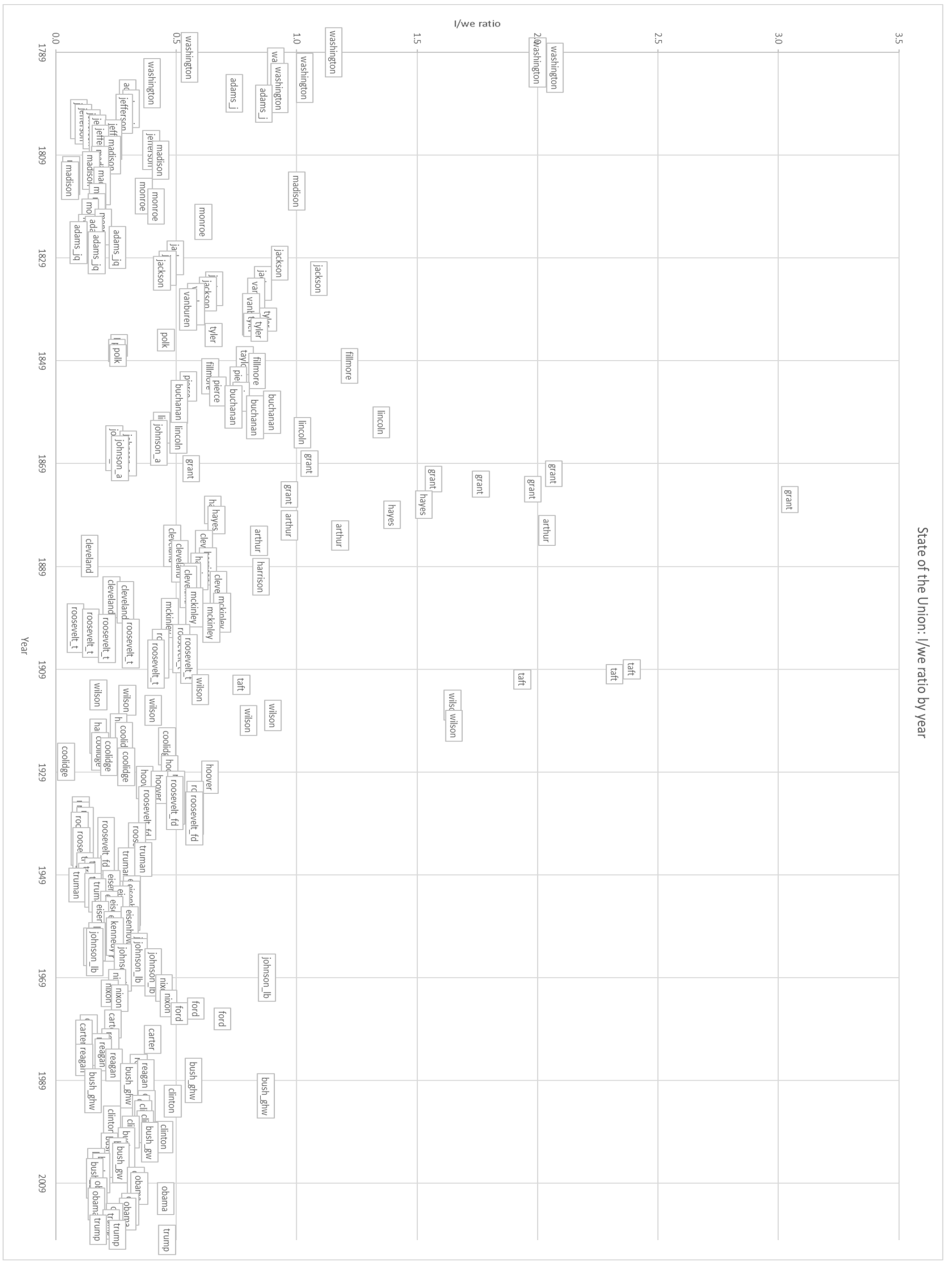




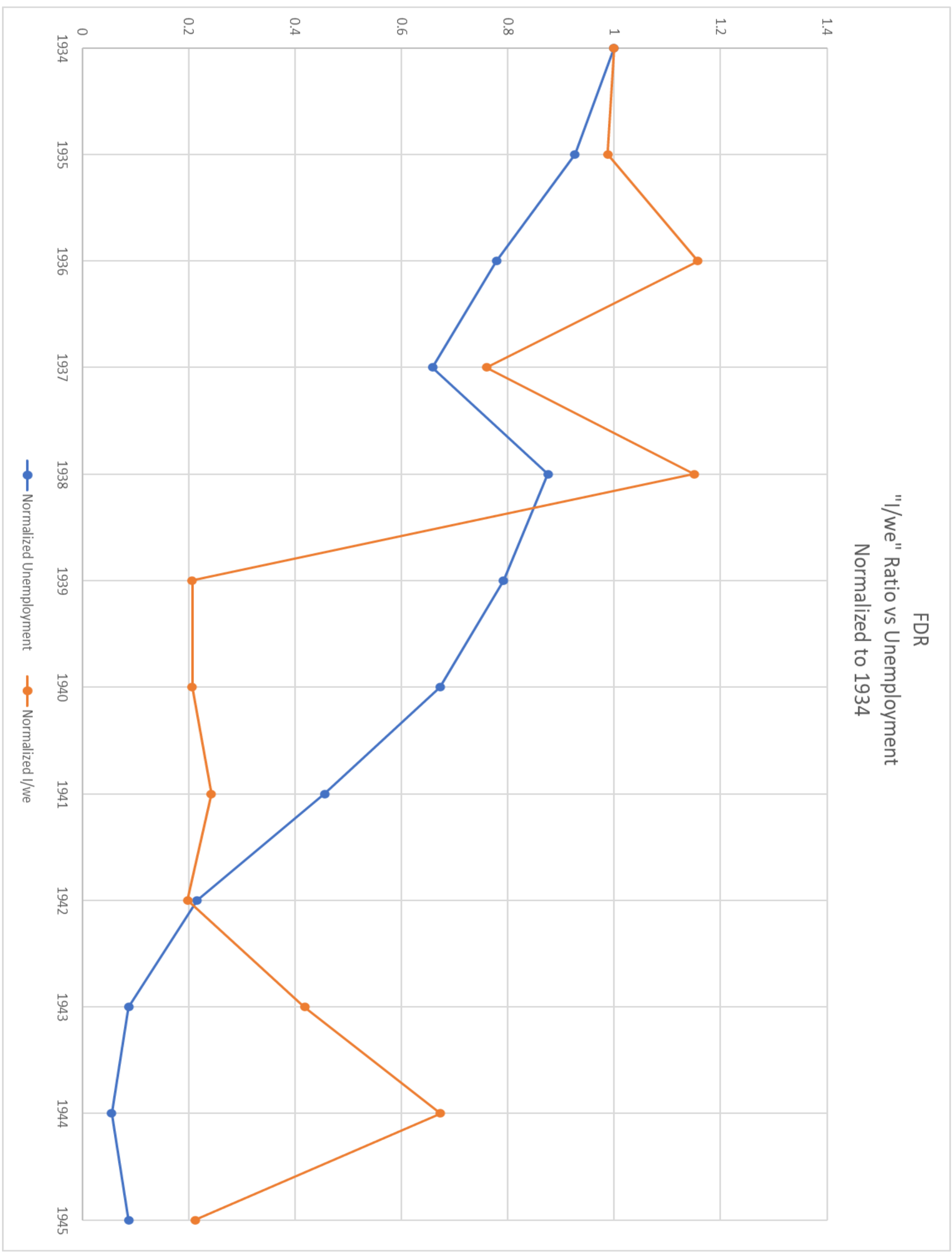




\section{Works Cited}

Fiedler, Klaus. Social Communication. Psychology Press, 2007. Open WorldCat, https://search.ebscohost.com/login.aspx?direct=true\&scope=site \&db=e000xna\&AN=360494.

Pennebaker, James W. The Secret Life of Pronouns: What Our Words Say about Us. Paperback ed, Bloomsbury, 2013.

Recession of 1937-38 | Federal Reserve History.

https://www.federalreservehistory.org/essays/recession_of_1937_38. Accessed 26 May 2020.

State of the Union Speeches by United States Presidents - Wikisource, the Free Online Library. https://en.wikisource.org/wiki/Portal:State_of_the_Union_Speeches_by_United_States_Presiden ts. Accessed 25 May 2020. 